Article

\title{
Does Grazing Exclusion Improve Soil Carbon and Nitrogen Stocks in Alpine Grasslands on the Qinghai-Tibetan Plateau? A Meta-Analysis
}

\author{
Xiang Liu ${ }^{1}$, Haiyan Sheng ${ }^{2}$, Zhaoqi Wang ${ }^{1}$, Zhiwen Ma ${ }^{1,3, *}$, Xiaotao Huang ${ }^{4}$ and Lanhai Li ${ }^{5,6}$ (D) \\ 1 State Key Laboratory of Plateau Ecology and Agriculture, Qinghai University, Xining 810016, China; \\ xiangliucas@gmail.com (X.L.); wangzhaoqi_818@163.com (Z.W.) \\ 2 College of Agriculture and Animal Husbandry, Qinghai University, Xining 810016, China; \\ shenghaiyanqh@126.com \\ 3 College of Eco-Environmental Engineering, Qinghai University, Xining 810016, China \\ 4 Key Laboratory of Restoration Ecology for Cold Regions in Qinghai, Northwest Institute of Plateau Biology, \\ Chinese Academy of Sciences, Xining 810008, China; xthuang@nwipb.cas.cn \\ 5 State Key Laboratory of Desert and Oasis Ecology, Xinjiang Institute of Ecology and Geography, Chinese \\ Academy of Sciences, Urumqi 830011, China; lilh@ms.xjb.ac.cn \\ 6 Yili Station for Watershed Ecosystem Research, Chinese Academy of Sciences, Xinyuan 835800, China \\ * Correspondence: mazhiwen14@mails.ucas.ac.cn
}

Received: 28 December 2019; Accepted: 23 January 2020; Published: 29 January 2020

\begin{abstract}
Grazing exclusion has been widely used to restore the degraded alpine grasslands on the Qinghai-Tibetan Plateau (QTP). However, the dynamics of soil organic carbon (SOC) and soil total nitrogen (STN) pools after grazing exclusion and their controlling factors are currently less understood in this region. Here, a meta-analysis was conducted to quantitatively assess the changes in SOC and STN stocks in topsoil $(0-30 \mathrm{~cm})$ following grazing exclusion in three major grassland types (alpine meadow, alpine steppe, and alpine desert steppe) on the QTP and to explore the potential factors controlling the effects of grazing exclusion on SOC and STN stocks. The results showed that overall, grazing exclusion significantly increased SOC stock by $16.5 \%$ and STN stock by $11.2 \%$. Significant increases in both SOC and STN stocks were observed after grazing exclusion of alpine meadow. In contrast, grazing exclusion did not improve SOC and STN stocks in the other two grassland types. The difference in mean annual precipitation among grassland types was a likely reason for the different dynamics of SOC and STN stocks after grazing exclusion. The effect sizes of both SOC and STN stocks were positively related to the duration of grazing exclusion, and a positive relationship was detected between the effect size of SOC stock and that of STN stock, demonstrating that the dynamics of SOC and STN were closely coupled during the period of grazing exclusion. However, grazing exclusion had no impact on soil C:N ratio for all grassland types, indicating that soil C:N ratio was generally stable after grazing exclusion. Therefore, it is suggested that the increase in STN can support continuous SOC accumulation following grazing exclusion. In conclusion, the findings suggest that the effects of grazing exclusion on SOC and STN stocks differ among grassland types on the QTP, and grazing exclusion of alpine meadows may provide substantial opportunities for improving SOC and STN stocks in this region.
\end{abstract}

Keywords: fencing; soil organic carbon; soil nitrogen; grassland restoration; alpine region; systematic review 


\section{Introduction}

Soils are the largest terrestrial reservoir of carbon (C), containing approximately $1500 \mathrm{Pg}$ $\left(1 \mathrm{Pg}=10^{15} \mathrm{~g}\right)$ organic $\mathrm{C}$ in the top meter worldwide [1]. The amount is about twice as large as the atmospheric $\mathrm{C}$ pool and three times the biotic $\mathrm{C}$ pool [2]. Therefore, small changes in the soil organic carbon (SOC) pool may significantly influence the concentration of carbon dioxide $\left(\mathrm{CO}_{2}\right)$ in the atmosphere [3]. With rising levels of atmospheric $\mathrm{CO}_{2}$, there has been growing concern on SOC sequestration in recent years [4]. As one of the most widespread terrestrial ecosystems in the world, grasslands play a crucial role in the global C cycle and provide key ecosystem services [5]. It is estimated that grasslands store $10-30 \%$ of the global SOC with a $C$ sequestration rate of $0.5 \mathrm{Pg}$ $\mathrm{C}$ year $^{-1}[6]$. Due to the strong potential for $\mathrm{C}$ sequestration, grassland soils may act as a sink for atmospheric $\mathrm{CO}_{2}$ and contribute to the mitigation of climate change [7,8]. Since most of the uncultivated grasslands are grazed by large mammals, the effect of grazing on $\mathrm{SOC}$ is vital for $\mathrm{C}$ sequestration in grasslands [5]. Unfortunately, large areas of grasslands are experiencing overgrazing worldwide, which not only reduces the plant biodiversity and productivity but also modifies the structure and function of ecosystem, leading to a depletion of SOC stock [6,9]. In the context of climate change, the restoration of overgrazed grasslands is thus urgently needed to recover SOC levels.

Globally, a common practice for restoring overgrazed grasslands is grazing exclusion $[10,11]$. However, despite the effectiveness of grazing exclusion on grassland restoration, there is currently no consensus on how SOC stock changes following grazing exclusion. Although many studies reported increased SOC stock following grazing exclusion [12,13], some studies found negligible or decreased changes in SOC stock [14-17]. Furthermore, most studies estimated the changes in SOC stock after grazing exclusion by multiplying SOC concentration with soil bulk density (BD) to a fixed soil depth $[18,19]$. This method may lead to over- or underestimation of SOC stock when soil BD changes after grazing exclusion $[13,20]$. In fact, the elimination of livestock trampling and the increased accumulation of root biomass after grazing exclusion have considerable impacts on soil BD [14,21]. In this case, SOC stock should better be quantified with equivalent soil mass [20,22]. It has been demonstrated that the equivalent soil mass method produces more accurate results than the fixed depth method when evaluating the changes in SOC stock in response to land-use or management practice $[20,23]$. Although increasingly used, the equivalent soil mass method is still rarely employed to assess the dynamic of SOC stock after grazing exclusion.

In addition to $\mathrm{SOC}$, soil $\mathrm{N}$ in grasslands has also received much attention because it plays a key role in global biogeochemical cycles [6,24]. Moreover, the interactions of $\mathrm{C}$ and $\mathrm{N}$ in soils are of great importance for regulating the main ecological processes such as nutrient cycling and energy flow [25]. The relationship between soil total nitrogen (STN) status and SOC sequestration has been discussed in previous studies, some of which pointed out that the dynamic of STN determined whether the $C$ sink in terrestrial ecosystems could be sustained over the long-term [26,27]. Other studies claimed that $\mathrm{N}$ might be a major limitation for the formation of soil organic matter in grasslands, and then influenced SOC sequestration $[28,29]$. Consequently, the impact of grazing exclusion on STN stock should also be quantitatively assessed to better understand the effectiveness of grazing exclusion on improving SOC stock.

The Qinghai-Tibetan Plateau (QTP), known as the third pole of the world, is the highest, largest, and most unique type of plateau in the world with an area of 2.5 million $\mathrm{km}^{2}[13,30]$. Over $85 \%$ of the QTP is covered by alpine grasslands, which are principally used for yak and Tibetan sheep grazing [18]. However, it is estimated that almost 30\% of alpine grasslands in the QTP have been severely degraded due to the impacts of overgrazing, rodent activities, and climate change in recent decades [31,32]. Grassland degradation in this region has not only led to a decline in forage yield for livestock grazing but also induced a reduction in ecosystem services [18,33]. In 2003, China's state and local authorities initiated a national ecological project named "Returning Grazing Land to Grassland" to recover the degraded grasslands [34]. From then on, grazing exclusion has become a commonly used management practice for restoring the degraded alpine grasslands on the QTP $[11,19]$. Nevertheless, the dynamics 
of SOC and STN stocks after grazing exclusion and their controlling factors are currently not well understood in this region because of the inconsistent results in individual studies $[13,14,16,35]$.

Based on the dataset compiled from published studies, a meta-analysis was carried out to quantitatively assess the changes in SOC and STN stocks in topsoil $(0-30 \mathrm{~cm})$ after grazing exclusion in three major grassland types (alpine meadow, alpine steppe, and alpine desert steppe) on the QTP. Potential factors influencing the dynamics of SOC and STN stocks after grazing exclusion were also explored. The following hypotheses were tested: (1) grazing exclusion would improve both SOC and STN stocks because vegetation restoration could increase the inputs while reducing the outputs of soil organic matter; (2) the change in SOC stock was closely correlated to that in STN during the period of grazing exclusion.

\section{Materials and Methods}

\subsection{Data Compilation}

This meta-analysis was based on studies that investigated the impacts of grazing exclusion on SOC and STN dynamics in alpine grasslands of the QTP. Several databases including Web of Science, Google Scholar and China National Knowledge Infrastructure were employed to search peer-reviewed studies published before October 2019. The keywords used in the literature search including "grazing exclusion or fencing", "soil carbon or soil nitrogen or soil properties", "grassland or pasture", and "Qinghai-Tibetan Plateau or Qinghai or Tibet". To be included in this analysis, a study had to meet the following criteria: (1) studies should be conducted in natural grazed grasslands rather than in virgin grasslands or cultivated grasslands; (2) studies were carried out using paired-site chronosequence, making similar climatic and soil conditions for the grazing and grazing exclusion sites; (3) the duration of grazing exclusion should be at least one year; (4) SOC stock, STN stock, or both of them (0-30 cm soil layer) were presented or could be calculated based on concentrations of SOC and STN, BD, and sampling depth for both grazing and grazing exclusion sites. Since soil equivalent mass correction was performed to estimate changes in SOC and STN stocks after grazing exclusion in this study, soil BD of both grazing and grazing exclusion sites had to be presented or could be calculated according to stock and concentration of SOC or STN; (5) studies needed to provide sample sizes for both grazing and grazing exclusion sites. Applying these criteria, a total of 110 paired observations reported by 40 peer-reviewed publications were selected for further analyses (Figure 1 and Supplementary Table S1).

The raw data were either obtained from tables or extracted from digitizing graphs using the GetData Graph Digitizer (version 2.25, Sergei Fedorov, Moscow, Russian Federation). For each publication, the following information was also compiled when it was available: location (county, latitude, and longitude), elevation (m), mean annual temperature (MAT, ${ }^{\circ} \mathrm{C}$ ) mean annual precipitation (MAP, $\mathrm{mm}$ ), grassland type, the duration of grazing exclusion (year), sampling depth $(\mathrm{cm})$, aboveground biomass (AGB, $\mathrm{g} \mathrm{m}^{-2}$ ), and belowground biomass $\left(\mathrm{BGB}, \mathrm{g} \mathrm{m}^{-2}\right.$ ). Soil $\mathrm{C}: \mathrm{N}$ ratio (molar ratio) was calculated based on the concentrations of SOC and STN. The collected dataset was grouped into three categories according to grassland types (alpine meadow, alpine steppe, and alpine desert steppe) to assess whether the impacts of grazing exclusion on SOC and STN stocks could be different among grassland types. 


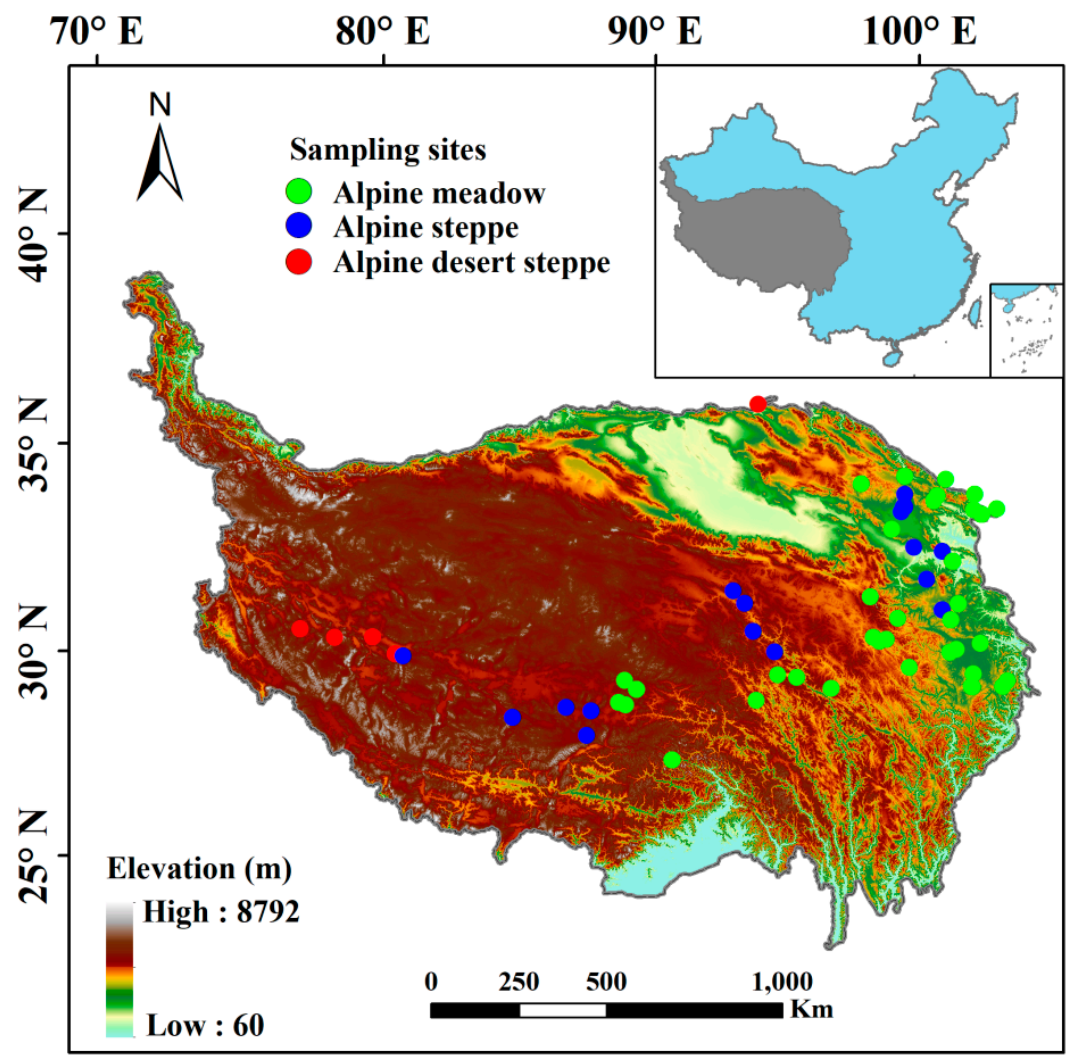

Figure 1. Sampling sites distribution of the individual studies included in this meta-analysis.

\subsection{Data Calculation}

In the present study, the minimum equivalent soil mass method, which adjusted soil mass to the lowest soil mass within each pair of sites, was employed to perform mass correction for both SOC and STN stocks. This method has been demonstrated as a better choice than the maximum equivalent soil mass method in native and restored grassland ecosystems where SOC concentrations decrease through the soil profile [20]. As described by Lee et al. [20] and Bárcena et al. [36], the first step of the minimum equivalent soil mass method was to calculate the mass per unit area of the soil according to a fixed depth in both grazing and grazing exclusion sites:

$$
M_{f d}=B D \times h \times 100
$$

where $M_{f d}$ is the dry soil mass to a fixed depth $\left(\mathrm{Mg} \mathrm{ha}^{-1}\right) ; B D$ is the bulk density $\left(\mathrm{g} \mathrm{cm}^{-3}\right)$; and $h$ is the thickness of soil layer $(\mathrm{cm})$. Second, the $M_{f d}$ in grazing and grazing exclusion sites was compared to select the site with the lightest soil mass, which was considered as the reference soil. A certain amount of soil mass $\left(M_{s u b}, \mathrm{Mg} \mathrm{ha}^{-1}\right)$ needed to be subtracted from the heavier soil, which had higher soil mass compared to the reference soil to obtain equivalent soil mass:

$$
M_{\text {sub }}=M_{f d}-M_{\text {equiv }}
$$

where $M_{\text {equiv }}$ is the equivalent soil mass $\left(\mathrm{Mg} \mathrm{ha}^{-1}\right)$. Finally, the SOC and STN stocks in equivalent soil mass were calculated using the following equations:

$$
\begin{gathered}
\text { Stock }=\text { Con } \times M \times 0.001, \\
\text { Stock }_{\text {equiv }}=\text { Stock }_{f d}-\text { Stock }_{\text {sub }},
\end{gathered}
$$


where Stock is the SOC or STN stock $\left(\mathrm{Mg} \mathrm{ha}^{-1}\right)$; Con is the concentration of SOC or STN $\left(\mathrm{g} \mathrm{kg}^{-1}\right)$; $M$ is the soil mass $\left(\mathrm{Mg} \mathrm{ha}^{-1}\right)$; Stock $_{\text {equiv }}$ is the SOC or STN stock in equivalent soil mass $\left(\mathrm{Mg} \mathrm{ha}^{-1}\right)$; Stock $_{f d}$ is the SOC or STN stock to a fixed depth $\left(\mathrm{Mg} \mathrm{ha}^{-1}\right)$; and Stock sub is the SOC or STN stock calculated for $M_{\text {sub }}\left(\mathrm{Mg} \mathrm{ha}^{-1}\right)$.

\subsection{Data Analysis}

To assess the differences in SOC stock, STN stocks, or soil C:N ratio between grazing and grazing exclusion sites, the natural log-transformed response ratio $(\ln R R)$ was used as the effect size:

$$
\ln (R R)=\ln \left(\frac{X_{G E}}{X_{G}}\right),
$$

where $X_{G E}$ and $X_{G}$ represent the mean SOC stock, STN stock, or soil C:N ratio at grazing exclusion sites and grazing sites, respectively. The results were transformed to the percentage changes $((R R-1) \times 100)$ to present the impacts of grazing exclusion on SOC stock, STN stock, and soil C:N ratio. Positive percentage changes indicated grazing exclusion increased SOC stock, STN stock, or soil C:N ratio, whereas negative values denoted reductions in SOC stock, STN stock, or soil C:N ratio after grazing exclusion [37,38].

In previous meta-analyses, the effect sizes were generally weighted by the inverse of pooled variance [11] or replication [37-39]. Since not all the collected studies reported the standard deviations of the mean values, and extreme weights might be induced by variance-based weighting function [40], the effect sizes were thus weighted by a function of replication [37-39]:

$$
\text { weight }=\frac{n_{G E} \times n_{G}}{n_{G E}+n_{G}}
$$

where $n_{G E}$ and $n_{G}$ are the numbers of replications of the treatment group (grazing exclusion) and control group (grazing), respectively.

Mean effect sizes and the $95 \%$ confidence intervals (CIs) were generated by a bootstrapping procedure based on 4999 iterations permutations using MetaWin 2.1 (Sinauer Associates, Sunderland, UK) [41]. It should be noted that a mixed-effects model or a fixed-effects model was technically not appropriate for non-parametric meta-analytic procedures based on weighting by replication. Nevertheless, a fixed-effects model had to be selected when running a correct bootstrapping using MetaWin [38]. The effects of grazing exclusion on SOC and STN stocks were deemed as significant if the $95 \%$ CIs did not overlap with zero. Means of different categorical variables were considered to be significantly different from one another if their $95 \%$ CIs were non-overlapping.

\section{Results}

\subsection{Frequency Distribution of Effect Sizes of SOC and STN Stocks}

As shown in Figure 2, the effect sizes of both SOC and STN stocks varied greatly among different observations. For both SOC and STN stocks, the frequency distribution of the effect sizes could be characterized by a Gaussian distribution. The mean effect sizes of SOC and STN stocks were 0.15 and 0.11, respectively. Among the 101 observations, 75 observations showed increases in SOC stock after grazing exclusion. In most cases, the effect sizes of SOC stock varied between -0.10 and 0.30 . Similarly, grazing exclusion led to increases in STN stock in most observations (83 of the total 103 observations). The effect sizes of STN stock were mainly distributed between -0.10 and 0.30 as well. 

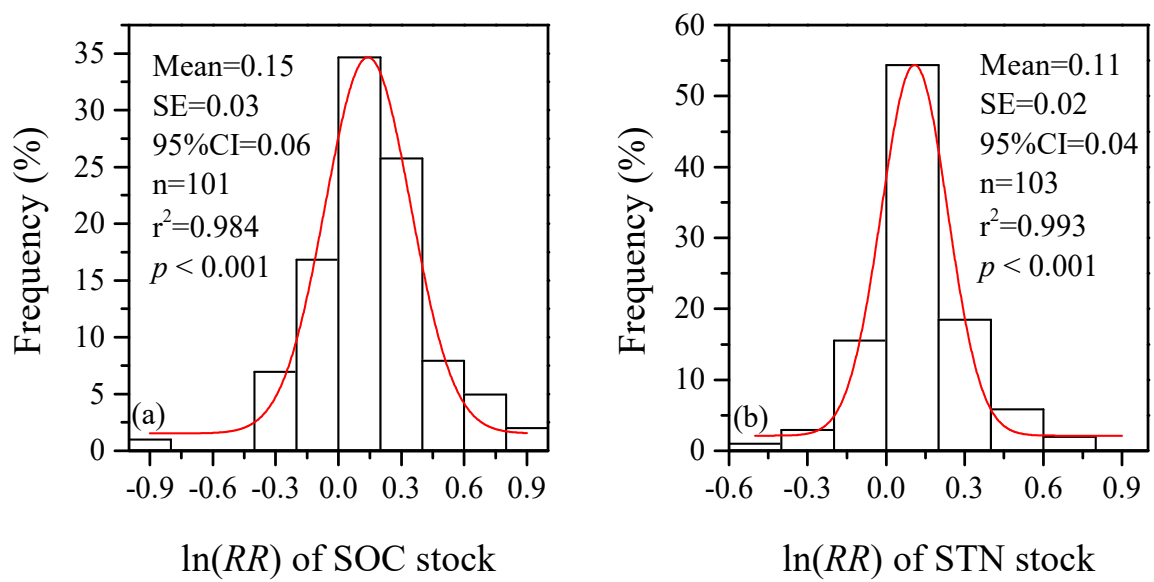

Figure 2. Frequency distributions of the effect sizes of soil organic carbon (SOC) (a) and soil total nitrogen (STN) (b) stocks among all observations. The curves were fitted by a Gaussian function. $\ln (R R)$ indicates response ratio.

\subsection{Changes in SOC and STN Stocks after Grazing Exclusion}

Across all the studies compiled in this meta-analysis, SOC stock significantly increased by $16.5 \%$ after grazing exclusion. For alpine meadow, grazing exclusion significantly increased SOC stock by $24.6 \%$, which was significantly higher than that after grazing exclusion of alpine steppe $(4.0 \%)$. Conversely, grazing exclusion led to a significant reduction in SOC stock $(-23.7 \%)$ in alpine desert steppe. The changes in SOC stock after grazing exclusion also differed significantly between alpine meadow and alpine desert steppe (Figure 3a). Overall, STN stock significantly increased by $11.2 \%$ after grazing exclusion. Grazing exclusion enhanced STN stock by $15.9 \%$ and $2.9 \%$ in alpine meadow and alpine steppe, respectively. Nevertheless, the increase was only significant in alpine meadow. Similar to SOC stock, STN stock showed a decreasing trend after grazing exclusion of alpine desert steppe, but the decrease $(-12.0 \%)$ was not significant. The changes in STN stock after grazing exclusion only differed significantly between alpine meadow and alpine desert steppe (Figure $3 b$ ).

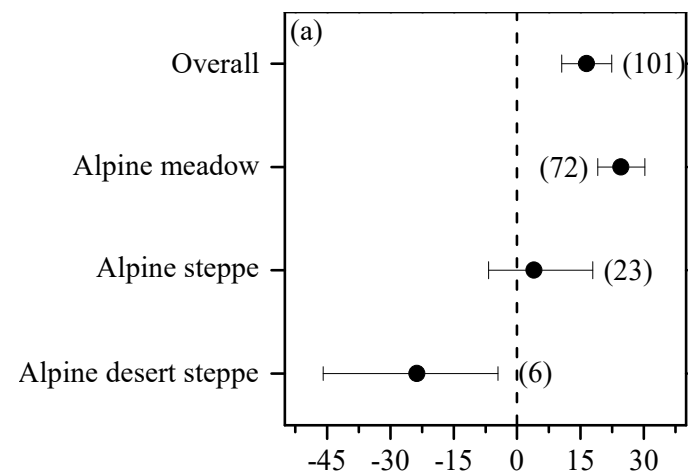

Relative changes in SOC stock (\%)

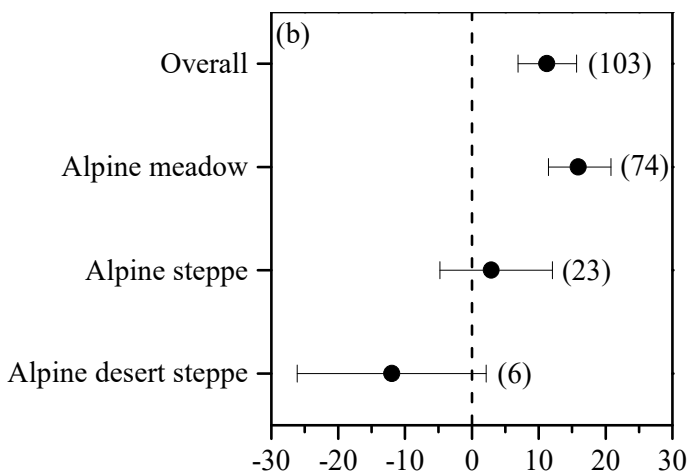

Relative changes in STN stock (\%)

Figure 3. Relative changes in soil organic carbon (SOC) (a) and soil total nitrogen (STN) (b) stocks after grazing exclusion. Points are means with $95 \%$ confidence intervals. Numbers of experimental observations are in parentheses.

\subsection{Effects of Grazing Exclusion on Soil C-N Coupling Relationship}

Overall, grazing exclusion increased soil C:N ratio by $2.3 \%$. For alpine meadow and alpine desert steppe, soil C: $\mathrm{N}$ ratio increased by $3.0 \%$ and $20.0 \%$ after grazing exclusion, respectively. In contrast, grazing exclusion of alpine steppe reduced soil C:N ratio by $5.2 \%$. Nevertheless, none of the changes were significant (Figure 4a). As illustrated in Figure 4b, significantly positive relationship was detected 
between the effect size of SOC stock and that of STN stock $\left(\mathrm{r}^{2}=0.490, p<0.001\right)$. In $73 \%$ observations, both SOC and STN stocks showed increasing trends after grazing exclusion. In contrast, nearly $14 \%$ observations found that grazing exclusion led to reductions in both SOC and STN stocks. The rest of observations found that grazing exclusion had opposite effects on SOC and STN stocks.

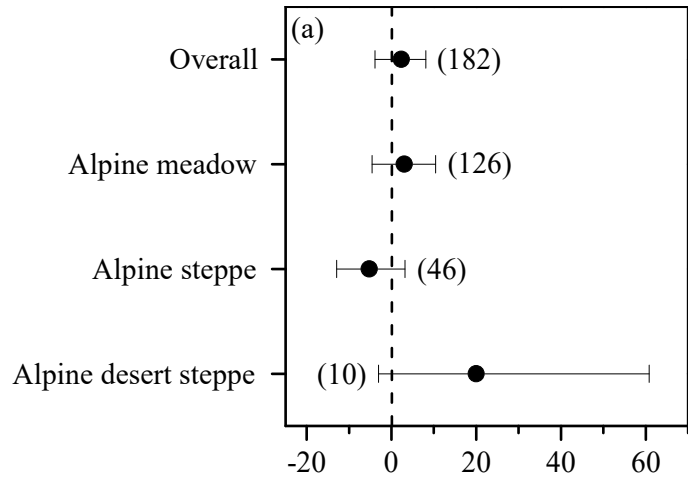

Relatvie changes in soil $\mathrm{C}: \mathrm{N}$ ratio $(\%)$

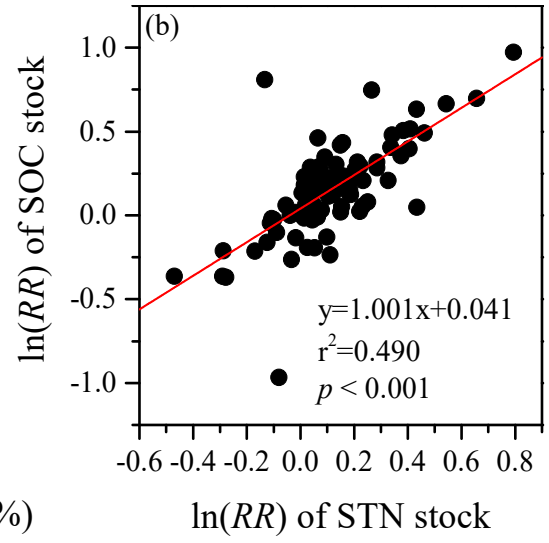

Figure 4. Effects of grazing exclusion on soil carbon-nitrogen (C-N) coupling relationship: (a) relative changes in soil C:N ratio after grazing exclusion; (b) relationship between the effect size of soil organic carbon (SOC) stock and that of soil total nitrogen (STN) stock. $\ln (R R)$ indicates response ratio.

\subsection{Relationships between MAT, MAP, the Duration of Grazing Exclusion, and the Effect Sizes of SOC and} STN Stocks

The Person correlation coefficients between MAT, MAP, the duration of grazing exclusion, and the effect sizes of SOC and STN stocks were presented in Table 1. The effect sizes of both SOC and STN stocks showed no relationship with MAT $(p>0.05)$. There was no relationship between the effect size of STN stock and MAP ( $p>0.05)$, which was positively correlated to the effect size of SOC stock ( $p<$ 0.05). By comparison, the duration of grazing exclusion showed positive relationships with the effect sizes of both SOC $(p<0.01)$ and STN stocks $(p<0.05)$. Although the relationships were statistically significant, it should be noted that the relationships were generally low as indicated by the low $\mathrm{r}$ values (0.242-0.310).

Table 1. Person correlation coefficients (r) between mean annul temperature (MAT), mean annual precipitation (MAP), the duration of grazing exclusion and the effect sizes of soil organic carbon (SOC) and soil total nitrogen (STN) stocks.

\begin{tabular}{ccccc}
\hline & \multicolumn{2}{c}{$\ln (\boldsymbol{R R})$ of SOC Stock } & \multicolumn{2}{c}{$\boldsymbol{\operatorname { l n } ( \boldsymbol { R } R ) \text { of STN Stock }}$} \\
\cline { 2 - 5 } & $\mathbf{r}$ & $\mathbf{n}$ & $\mathbf{r}$ & $\mathbf{n}$ \\
\hline MAT $\left({ }^{\circ} \mathrm{C}\right)$ & 0.081 & 97 & 0.132 & 100 \\
MAP $(\mathrm{mm})$ & $\mathbf{0 . 2 4 7 ^ { * }}$ & 98 & 0.193 & 100 \\
Duration (year) & $\mathbf{0 . 3 1 0 ^ { * * }}$ & 98 & $\mathbf{0 . 2 4 2}$ & 101 \\
\hline
\end{tabular}

Bold values indicate correlations are significant $(p<0.05$ or 0.01$)$; $\ln (R R)$ indicates response ratio; ${ }^{*} p<0.05$; $* * p<0.01$.

\subsection{Relationships between the Effect Sizes of SOC Stock, STN Stock, AGB and BGB}

As shown in Figure 5a,b, the effect sizes of both SOC $\left(\mathrm{r}^{2}=0.185, p<0.001\right)$ and STN stocks $\left(r^{2}=0.251, p<0.001\right)$ were positively correlated to that of AGB. Positive relationship was also observed between the effect size of SOC stock and that of BGB $\left(\mathrm{r}^{2}=0.125, p<0.05\right)$ (Figure 5c). Similarly, the effect size of STN stock showed a positive relationship with that of BGB $\left(\mathrm{r}^{2}=0.161, p<0.01\right)$ (Figure $5 \mathrm{~d}$ ). However, the relationships between the effect sizes of SOC stock, STN stock, AGB, and BGB were generally weak because the $\mathrm{r}^{2}$ values were low. 

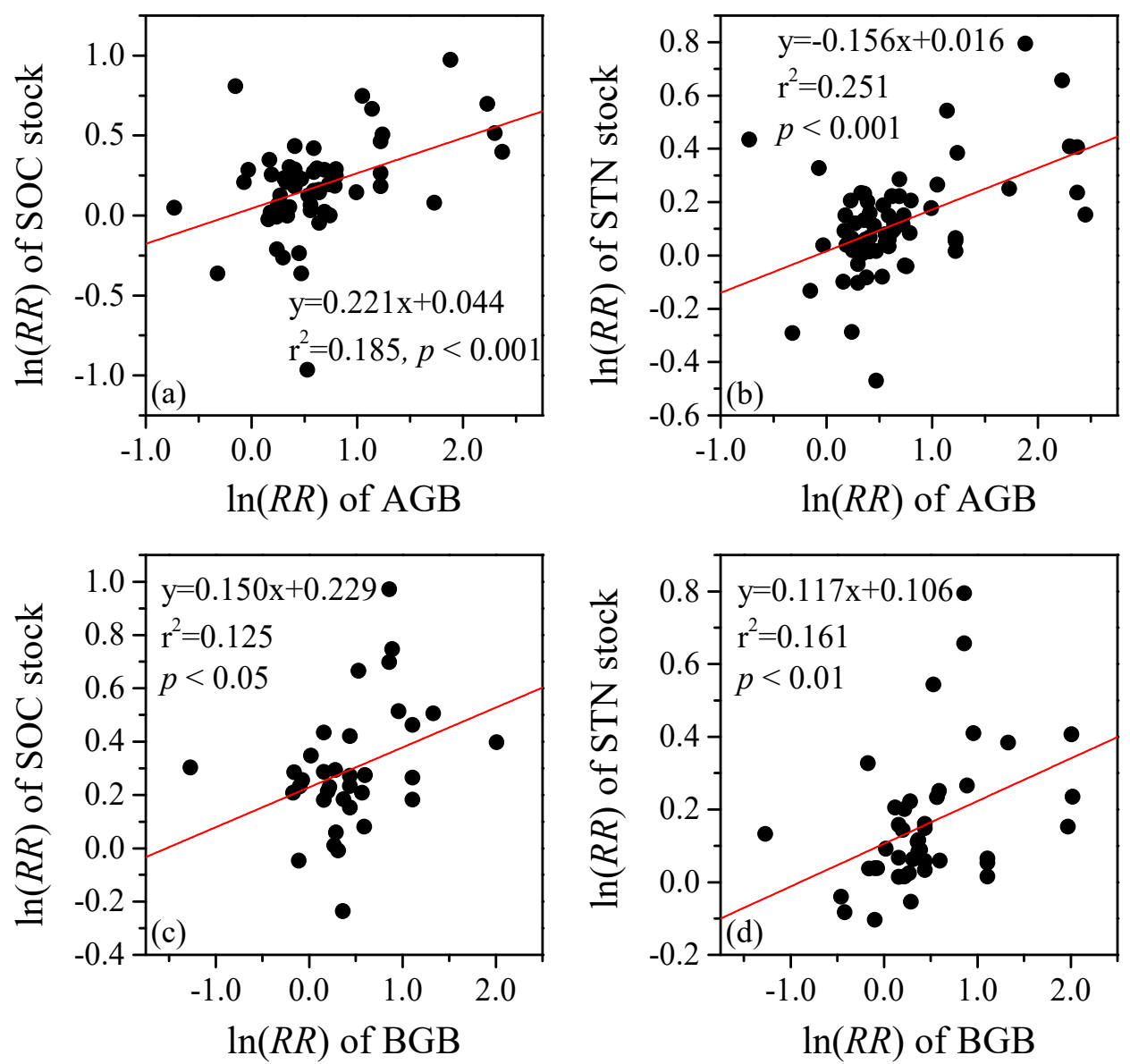

Figure 5. Relationships between: (a) the effect size of soil organic carbon (SOC) stock and that of aboveground biomass (AGB); (b) the effect size of soil organic nitrogen (STN) stock and that of AGB; (c) the effect size of SOC stock and that of belowground biomass (BGB); (d) the effect size of STN stock and that of BGB. $\ln (R R)$ indicates response ratio.

\section{Discussion}

\subsection{Overall Effects of Grazing Exclusion on SOC and STN Stocks}

Overall, the results of this meta-analysis showed that grazing exclusion significantly enhanced both SOC (16.5\%) and STN (11.2\%) stocks in topsoil, supporting the first hypothesis that grazing exclusion would improve both SOC and STN stocks in alpine grasslands of the QTP. The results were in agreement with those of previous syntheses [10,34,42]. For example, Xiong et al. [10] found that SOC stock in the upper $30 \mathrm{~cm}$ soil layer significantly increased by $14.4 \%$ after grazing exclusion in grasslands across China. Since $\mathrm{C}$ and $\mathrm{N}$ dynamics in soils are primarily determined by the balance between the inputs (e.g., litter and dead roots) and the outputs (e.g., decomposition) of soil organic matter [37,43], there are several underlying mechanisms responsible for the increased SOC and STN stocks after grazing exclusion. First, the removal of grazing pressure reduced the outputs of $\mathrm{C}$ and $\mathrm{N}$ from the ecosystem to livestock and increased the net primary productivity of grasslands (Figure 5) [34,44,45]. In this case, the inputs of organic matter into the soils might increase. Second, grazing exclusion improved the capacity of soil water conservation by reducing bare soil water evaporation because of the increased vegetation height, coverage, and mulch. The improved soil moisture further led to a higher plant productivity and soil organic matter inputs [34]. Third, the exclusion of livestock trampling might promote the physical protection of soil organic matter by increasing soil aggregate, slowing down the decomposition of soil organic matter [46,47]. Fourth, the increased proportion of leguminous species in plant community after grazing exclusion might contribute to STN accumulation 
through biological $\mathrm{N}$ fixation [48]. However, the relative importance of these mechanisms in improving SOC and STN stocks during the period of grazing exclusion remains unclear and needs to be focused on in future studies.

\subsection{Factors Controlling the Effects of Grazing Exclusion on SOC and STN Stocks}

In alpine regions, both temperature and evapotranspiration are low because of the high elevation. Hence, SOC is difficult to decompose and mostly remains in soils for a long time in alpine grasslands [49]. It was estimated that the $C$ stored in the soils of alpine grasslands accounted for more than half of the total SOC stock in grasslands of China, indicating a significant role of alpine grassland soils in regulating climate change [50]. Previous studies have pointed out that SOC and STN stocks differ considerably among different grassland types on the QTP [50,51]. Nevertheless, whether the effectiveness of grazing exclusion on improving SOC and STN stocks can be different in alpine meadow, alpine steppe, and alpine desert steppe-three major grassland types on the QTP—remains unclear. In this study, significant increases in both SOC (24.6\%) and STN stocks $(15.9 \%)$ were observed after grazing exclusion of alpine meadow (Figure 3), demonstrating that grazing exclusion was an effective management practice for enhancing SOC and STN stocks in alpine meadow of the QTP. In contrast, grazing exclusion of alpine steppe had no impact on both SOC (4.0\%) and STN stocks (2.9\%), and grazing exclusion of alpine desert steppe only significantly altered SOC stock (-23.7\%) (Figure 3). The results implied that grazing exclusion might not be a promising way to recover SOC and STN levels in alpine steppe and alpine desert steppe on the QTP. Climatic conditions are common factors used for the classification of grassland type [52]. The relationships between SOC stock, MAT, and MAP in grasslands were reported in previous studies, most of which found that SOC or STN stock was positively correlated to MAP $[10,53,54]$. In contrast, there is currently no consensus on the relationship between SOC or STN stock and MAT because of the inconsistent results in individual studies $[10,34,53]$. In the present study, the effect sizes of both SOC and STN stocks were unrelated to MAT (Table 1), suggesting that MAT was not a key factor regulating the impacts of grazing exclusion on SOC and STN stocks in alpine grasslands of the QTP. By comparison, a positive relationship was observed between the effect size of SOC stock and MAP (Table 1), although the relationship was weak. The result indicated that the effectiveness of grazing exclusion on improving SOC stock might increase with MAP, which was generally higher in alpine meadow than in alpine steppe and alpine desert steppe [55]. This was possibly due to the fact that plant productivity usually increased with MAP in alpine grasslands of the QTP, leading to higher inputs of soil organic matter in alpine meadow than those in other two grassland types [55,56]. Since nearly $60 \%$ of the grasslands on the QTP are alpine meadows, it is suggested that grazing exclusion of alpine meadow may provide substantial opportunities for improving SOC and STN levels on the QTP.

Empirical evidence has indicated that the duration of grazing exclusion plays a crucial role in determining the dynamics of SOC and STN stocks after grazing exclusion $[10,42,57]$. The results of this meta-analysis showed that the effect sizes of both SOC and STN stocks were positively correlated to the duration of grazing exclusion (Table 1), demonstrating that both SOC and STN stocks increased with the duration of grazing exclusion. In the compiled studies, the duration of grazing exclusion varied from 1 year to 11 years. Compared to short-term grazing exclusion, grazing exclusion with longer years often leads to higher plant productivity and coverage because the exclusion of livestock grazing creates a suitable environment for plant growth [58]. In this case, the inputs of soil organic matter (e.g., litter and dead roots) may increase with the duration of grazing exclusion and contribute to continuous accumulations in both SOC and STN stocks. Moreover, similar to the findings of Deng et al. [34], the results of this study showed that there was no relationship between the annual change in SOC or STN stock $\left(\%\right.$ year $\left.^{-1}\right)$ and the duration of grazing exclusion (Supplementary Table S2), suggesting that the duration of grazing exclusion did not affect the variation rate of SOC or STN stock. Therefore, it is suggested that the duration of grazing exclusion may not be a key factor determining the effectiveness of grazing exclusion on improving SOC and STN stocks in alpine grasslands of the QTP, at least within 
the first decade following grazing exclusion. Nevertheless, some studies found that long-term grazing exclusion could induce a decline of plant biodiversity because plant species with weaker competitive ability might disappear from the plant community $[48,57,59]$. Consequently, the balance between SOC recovery and plant biodiversity maintenance should be paid closer attention to in the future to explore the optimum exclusion duration in alpine grasslands of the QTP.

\subsection{C-N Interactions}

Since additional $\mathrm{N}$ is required to support terrestrial $\mathrm{C}$ sequestration due to stoichiometric relationship in soils, the availability of $\mathrm{N}$ is thus crucial for determining whether the $\mathrm{C}$ sink in terrestrial ecosystems can be sustained over the long-term [26,27]. As illustrated above, both SOC and STN stocks showed increasing trends with the duration of grazing exclusion (Table 1), and a positive relationship was detected between the effect size of SOC stock and that of STN stock (Figure 3b). The results implied that the dynamics of SOC and STN during the period of grazing exclusion were strongly coupled in alpine grasslands of the QTP. Moreover, the results of this study showed that grazing exclusion had no impact on soil C:N ratio for all grassland types on the QTP (Figure 4a). The results were in agreement with those of previous syntheses [11,34,42]. For example, Hu et al. [42] pointed out that there was no significant change in soil C:N ratio if the duration of grazing exclusion was less than 15 years. Yu et al. [11] observed that the differences in soil C: $\mathrm{N}$ ratio between grazing sites and grazing exclusion sites were not significant at all stages of grazing exclusion. The stable soil C:N ratio after grazing exclusion indicated that $\mathrm{N}$ might not be a limiting factor of SOC accumulation during the period of grazing exclusion in alpine grasslands of the QTP. Hence, it is suggested that the increase in STN may support continuous SOC accumulation following grazing exclusion in alpine grasslands of the QTP.

\section{Conclusions}

In this meta-analysis, it was observed that grazing exclusion significantly increased SOC $(16.5 \%)$ and STN $(11.2 \%)$ stocks in the upper $30 \mathrm{~cm}$ soil layer in alpine grasslands of the QTP. The impacts of grazing exclusion on SOC and STN stocks differed considerably among different grassland types. For alpine meadow, grazing exclusion significantly enhanced SOC and STN stocks by $24.6 \%$ and $15.9 \%$, respectively. However, neither SOC nor STN stocks showed increasing trends after grazing exclusion of alpine steppe and alpine desert steppe. The difference in MAP among the three grassland types was a likely reason for the different dynamics of SOC and STN stocks following grazing exclusion. Hence, it is suggested that grazing exclusion is an effective management practice for recovering SOC and STN levels in alpine meadow on the QTP. Both SOC and STN stocks increased with the duration of grazing exclusion, as indicated by the positive relationship between the effect size of SOC or STN stock and the duration of grazing exclusion. However, the variation rates of both SOC and STN stocks were unrelated to the duration of grazing exclusion, suggesting that the duration of grazing exclusion did not influence the effectiveness of grazing exclusion on improving SOC and STN stocks. A positive relationship was detected between the effect size of SOC stock and that of STN stock. Moreover, grazing exclusion had no impact on soil $\mathrm{C}: \mathrm{N}$ ratio for all grassland types. The results indicated that the dynamics of SOC and STN were strongly coupled and the increase in STN could support continuous SOC accumulation during the period of grazing exclusion. The trade-off between SOC accumulation and plant biodiversity maintenance should be paid more attention in further studies to explore the optimum exclusion duration in this region.

Supplementary Materials: The following are available online at http://www.mdpi.com/2071-1050/12/3/977/s1, Table S1. List of studies included in this meta-analysis.; Table S2. Person correlation coefficients (r) between the annual soil organic carbon (SOC) stock change, the annual soil total nitrogen (STN) change, mean annual temperature (MAT), mean annual precipitation (MAP), and the duration of grazing exclusion.

Author Contributions: Conceptualization, X.L. and Z.M.; Data curation, X.L.; Funding acquisition, L.L.; Software, X.L. and Z.W.; Writing-review and editing, X.L., H.S., Z.M., X.H. and L.L. All authors have read and agreed to the published version of the manuscript. 
Funding: This study was supported by the Strategic Priority Research Program of the Chinese Academy of Sciences, Pan-Third Pole Environment Study for a Green Silk Road (Pan-TPE) (No. XDA20040300).

Acknowledgments: The authors are grateful to the authors of the cited literature for their constructive original research and the anonymous referees for their valuable suggestions for improving the manuscript.

Conflicts of Interest: The authors declare no conflict of interest.

\section{References}

1. Batjes, N.H. Total carbon and nitrogen in the soils of the world. Eur. J. Soil Sci. 1996, 47, 151-163. [CrossRef]

2. Smith, P. Land use change and soil organic carbon dynamics. Nutr. Cycl. Agroecosyst. 2008, 81, 169-178. [CrossRef]

3. Stockmann, U.; Adams, M.A.; Crawford, J.W.; Field, D.J.; Henakaarchchi, N.; Jenkins, M.; Minasny, B.; McBratney, A.B.; de Remy de Courcells, V.; Singh, K.; et al. The knowns, known unknowns and unknowns of sequestration of soil organic carbon. Agric. Ecosyst. Environ. 2013, 164, 80-99. [CrossRef]

4. Lal, R.; Negassa, W.; Lorenz, K. Carbon sequestration in soil. Curr. Opin. Environ. Sustain. 2015, 15, 79-86. [CrossRef]

5. McSherry, M.E.; Ritchie, M.E. Effects of grazing on grassland soil carbon: A global review. Glob. Chang. Biol. 2013, 19, 1347-1357. [CrossRef]

6. Zhou, G.; Zhou, X.; He, Y.; Shao, J.; Hu, Z.; Liu, R.; Zhou, H.; Hosseinibai, S. Grazing intensity significantly affects belowground carbon and nitrogen cycling in grassland ecosystems: A meta-analysis. Glob. Chang. Biol. 2017, 23, 1167-1179. [CrossRef] [PubMed]

7. Scurlock, J.M.O.; Hall, D.O. The global carbon sink: A grassland perspective. Glob. Chang. Biol. 1998, 4, 229-233. [CrossRef]

8. Conant, R.T.; Cerri, C.E.P.; Osborne, B.B.; Paustian, K. Grassland management impacts on soil carbon stocks: A new synthesis. Ecol. Appl. 2017, 27, 662-668. [CrossRef] [PubMed]

9. Dlamini, P.; Chivenge, P.; Chaplot, V. Overgrazing decreases soil organic carbon stocks the most under dry climates and low soil pH: A meta-analysis shows. Agric. Ecosyst. Environ. 2016, 221, 258-269. [CrossRef]

10. Xiong, D.; Shi, P.; Zhang, X.; Zou, C.B. Effects of grazing exclusion on carbon sequestration and plant diversity in grasslands of China-A meta-analysis. Ecol. Eng. 2016, 94, 647-655. [CrossRef]

11. Yu, L.; Chen, Y.; Sun, W.; Huang, Y. Effects of grazing exclusion on soil carbon dynamics in alpine grasslands of the Tibetan Plateau. Geoderma 2019, 353, 133-143. [CrossRef]

12. Luan, J.; Cui, L.; Xiang, C.; Wu, J.; Song, H.; Ma, Q.; Hu, Z. Different grazing removal exclosures effects on soil C stocks among alpine ecosystems in east Qinghai-Tibet Plateau. Ecol. Eng. 2014, 64, 262-268. [CrossRef]

13. Ma, W.; Ding, K.; Li, Z. Comparison of soil carbon and nitrogen stocks at grazing-excluded and yak grazed alpine meadow sites in Qinghai-Tibetan Plateau, China. Ecol. Eng. 2016, 87, 203-211. [CrossRef]

14. Lu, X.; Yan, Y.; Sun, J.; Zhang, X.; Chen, Y.; Wang, X.; Cheng, G. Short-term grazing exclusion has no impact on soil properties and nutrients of degraded alpine grassland in Tibet, China. Solid Earth 2015, 6, 1195-1205. [CrossRef]

15. Aynekulu, E.; Mekuria, W.; Tsegaye, D.; Feyissa, K.; Angassa, A.; de Leeuw, J.; Shepherd, K. Long-term livestock exclosure did not affect soil carbon in southern Ethiopian rangelands. Geoderma 2017, 307, 1-7. [CrossRef]

16. Hafner, S.; Unteregelsbacher, S.; Seeber, E.; Lena, B.; Xu, X.; Li, X.; Guggenberger, G.; Miehe, G.; Kuzyakov, Y. Effect of grazing on carbon stocks and assimilate partitioning in a Tibetan montane pasture revealed by ${ }^{13} \mathrm{CO}_{2}$ pulse labeling. Glob. Chang. Biol. 2012, 18, 528-538. [CrossRef]

17. Orgill, S.E.; Condon, J.R.; Conyers, M.K.; Morris, S.G.; Alcock, D.J.; Murphy, B.W.; Greene, R.S.B. Removing grazing pressure from a native pasture decreases soil organic carbon in southern New South Wales, Australia. Land Degrad. Dev. 2018, 29, 274-283. [CrossRef]

18. Li, Y.Y.; Dong, S.K.; Wen, L.; Wang, X.X.; Wu, Y. Soil carbon and nitrogen pools and their relationship to plant and soil dynamics of degraded and artificially restored grasslands of the Qinghai-Tibetan Plateau. Geoderma 2014, 213, 178-184. [CrossRef]

19. Lu, X.; Yan, Y.; Sun, J.; Zhang, X.; Chen, Y.; Wang, X.; Cheng, G. Carbon, nitrogen, and phosphorus storage in alpine grassland ecosystems of Tibet: Effects of grazing exclusion. Ecol. Evol. 2015, 5, 4492-4504. [CrossRef] 
20. Lee, J.; Hopmans, J.W.; Rolston, D.E.; Baer, S.G.; Six, J. Determining soil carbon stock changes: Simple bulk density corrections fail. Agri. Ecosyst. Environ. 2009, 134, 251-256. [CrossRef]

21. Chai, J.; Yu, X.; Xu, C.; Xiao, H.; Zhang, J.; Yang, H.; Pan, T. Effects of yak and Tibetan sheep trampling on soil properties in the northeastern Qinghai-Tibetan Plateau. Appl. Soil Ecol. 2019, 144, 147-154. [CrossRef]

22. Wendt, J.W.; Hauser, S. An equivalent soil mass procedure for monitoring soil organic carbon in multiple soil layers. Eur. J. Soil Sci. 2013, 64, 58-65. [CrossRef]

23. Ellert, B.H.; Bettany, J.R. Calculation of organic matter and nutrients stored in soils under contrasting management regimes. Can. J. Soil Sci. 1995, 75, 529-538. [CrossRef]

24. Bouwman, A.F.; Beusen, A.H.W.; Billen, G. Human alteration of the global nitrogen and phosphorus soil balances for the period 1970-2050. Global Biogeochem. Cycles 2009, 23, GB0A04. [CrossRef]

25. Sardans, J.; Rivas-Ubach, A.; Peñuelas, J. The C:N:P stoichiometry of organisms and ecosystems in a changing world: A review and perspectives. Perspect. Plant. Ecol. Evol. Syst. 2012, 14, 33-47. [CrossRef]

26. Rastetter, E.B.; Ågren, G.I.; Shaver, G.R. Responses of N-limited ecosystems to increased $\mathrm{CO}_{2}$ : A balanced-nutrition, coupled-element-cycles model. Ecol. Appl. 1997, 7, 444-460. [CrossRef]

27. Luo, Y.; Su, B.O.; Currie, W.S.; Dukes, J.S.; Finzi, A.; Hartwig, U.; Hungate, B.; McMurtrie, R.E.; Oren, R.; Parton, W.J.; et al. Progressive nitrogen limitation of ecosystem responses to rising atmospheric carbon dioxide. Bioscience 2004, 54, 731-739. [CrossRef]

28. Piñeiro, G.; Paruelo, J.M.; Oesterheld, M.; Jobbágy, E.G. Pathways of grazing effects on soil organic carbon and nitrogen. Rangel. Ecol. Manag. 2010,63, 109-119. [CrossRef]

29. van Groenigen, J.W.; Van Kessel, C.; Hungate, B.A.; Oenema, O.; Powlson, D.S.; van Groenigen, K.J. Sequestering soil organic carbon: A nitrogen dilemma. Environ. Sci. Technol. 2017, 51, 4738-4739. [CrossRef]

30. Zhao, J.; Li, X.; Li, R.; Tian, L.; Zhang, T. Effect of grazing exclusion on ecosystem respiration among three different alpine grasslands on the central Tibetan Plateau. Ecol. Eng. 2016, 94, 599-607. [CrossRef]

31. Harris, R.B. Rangeland degradation on the Qinghai-Tibetan plateau: A review of the evidence of its magnitude and causes. J. Arid Environ. 2010, 74, 1-12. [CrossRef]

32. Li, Y.; Dong, S.; Wen, L.; Wang, X.; Wu, Y. The effects of fencing on carbon stocks in the degraded alpine grasslands of the Qinghai-Tibetan Plateau. J. Environ. Manage. 2013, 128, 393-399. [CrossRef] [PubMed]

33. Zhang, W.; Xue, X.; Peng, F.; You, Q.; Hao, A. Meta-analysis of the effects of grassland degradation on plant and soil properties in the alpine meadows of the Qinghai-Tibetan Plateau. Glob. Ecol. Conserv. 2019, 20, e00774. [CrossRef]

34. Deng, L.; Shangguan, Z.P.; Wu, G.L.; Chang, X.F. Effects of grazing exclusion on carbon sequestration in China's grassland. Earth Sci. Rev. 2017, 173, 84-95. [CrossRef]

35. Shi, X.M.; Li, X.G.; Li, C.T.; Zhao, Y.; Shang, Z.H.; Ma, Q. Grazing exclusion decreases soil organic C storage at an alpine grassland of the Qinghai-Tibetan Plateau. Ecol. Eng. 2013, 57, 183-187. [CrossRef]

36. Bárcena, T.G.; Kiær, L.P.; Vesterdal, L.; Stefánsdóttir, H.M.; Gundersen, P.; Sigurdsson, B.D. Soil carbon stock change following afforestation in Northern Europe: A meta-analysis. Glob. Chang. Biol. 2014, 20, 2393-2405. [CrossRef] [PubMed]

37. Liu, X.; Yang, T.; Wang, Q.; Huang, F.; Li, L. Dynamics of soil carbon and nitrogen stocks after afforestation in arid and semi-arid regions: A meta-analysis. Sci. Total Environ. 2018, 618, 1658-1664. [CrossRef]

38. Xia, L.; Lam, S.K.; Wolf, B.; Kiese, R.; Chen, D.; Butterbach-Bahl, K. Trade-offs between soil carbon sequestration and reactive nitrogen losses under straw return in global agroecosystems. Glob. Chang. Biol. 2018, 24, 5919-5932. [CrossRef]

39. Lam, S.K.; Chen, D.; Norton, R.; Armstrong, R.; Mosier, A.R. Nitrogen dynamics in grain crop and legume pasture systems under elevated atmospheric carbon dioxide concentration: A meta-analysis. Glob. Chang. Biol. 2012, 18, 2853-2859. [CrossRef]

40. van Groenigen, K.J.; Osenberg, C.W.; Hungate, B.A. Increased soil emissions of potent greenhouse gases under increased atmospheric $\mathrm{CO}_{2}$. Nature 2011, 475, 214-216. [CrossRef]

41. Rosenberg, M.S.; Adams, D.C.; Gurevitch, J. METAWIN, Statistical Software for Meta-Analysis, version 2; Sinauer: Sunderland, MA, USA, 2000.

42. Hu, Z.; Li, S.; Guo, Q.; Niu, S.; He, N.; Li, L.; Yu, G. A synthesis of the effect of grazing exclusion on carbon dynamics in grasslands in China. Glob. Chang. Biol. 2016, 22, 1385-1393. [CrossRef] [PubMed]

43. McLauchlan, K. The nature and longevity of agricultural impacts on soil carbon and nutrients: A review. Ecosystems 2006, 9, 1364-1382. [CrossRef] 
44. Tanentzap, A.J.; Coomes, D.A. Carbon storage in terrestrial ecosystems: Do browsing and grazing herbivores matter? Biol. Rev. 2012, 87, 72-94. [CrossRef] [PubMed]

45. Fernández-Lugo, S.; Bermejo, L.A.; de Nascimento, L.; Méndez, J.; Naranjo-Cigala, A.; Arévalo, J.R. Productivity: Key factor affecting grazing exclusion effects on vegetation and soil. Plant. Ecol. 2013, 214, 641-656. [CrossRef]

46. Wiesmeier, M.; Steffens, M.; Mueller, C.W.; Kölbl, A.; Reszkowska, A.; Peth, S.; Horn, R.; Kögel-Knabner, I. Aggregate stability and physical protection of soil organic carbon in semi-arid steppe soils. Eur. J. Soil Sci. 2012, 63, 22-31. [CrossRef]

47. Wen, D.; He, N.; Zhang, J. Dynamics of soil organic carbon and aggregate stability with grazing exclusion in the Inner Mongolian grasslands. PLoS ONE 2016, 11, e0146757. [CrossRef]

48. Wu, G.L.; Du, G.Z.; Liu, Z.H.; Thirgood, S. Effect of fencing and grazing on a Kobresia-dominated meadow in the Qinghai-Tibetan Plateau. Plant. Soil 2009, 319, 115-126. [CrossRef]

49. Ni, J. Carbon storage in grasslands of China. J. Arid Environ. 2002, 50, 205-218. [CrossRef]

50. Genxu, W.; Ju, Q.; Guodong, C.; Yuanmin, L. Soil organic carbon pool of grassland soils on the Qinghai-Tibetan Plateau and its global implication. Sci. Total Environ. 2002, 291, 207-217. [CrossRef]

51. Yang, Y.; Fang, J.; Tang, Y.; Ji, C.; Zheng, C.; He, J.; Zhu, B. Storage, patterns and controls of soil organic carbon in the Tibetan grasslands. Glob. Chang. Biol. 2008, 14, 1592-1599. [CrossRef]

52. Ren, J.Z.; Hu, Z.Z.; Zhao, J.; Zhang, D.G.; Hou, F.J.; Lin, H.L.; Mu, X.D. A grassland classification system and its application in China. Rangeland J. 2008, 30, 199-209. [CrossRef]

53. Yang, Y.; Fang, J.; Ma, W.; Smith, P.; Mohammat, A.; Wang, S.; Wang, W. Soil carbon stock and its changes in northern China's grasslands from 1980s to 2000s. Glob. Chang. Biol. 2010, 16, 3036-3047. [CrossRef]

54. Wiesmeier, M.; Hübner, R.; Barthold, F.; Spörlein, P.; Geuß, U.; Hangen, E.; Reischl, A.; Schilling, B.; von Lützow, M.; Kögel-Knabner, I. Amount, distribution and driving factors of soil organic carbon and nitrogen in cropland and grassland soils of southeast Germany (Bavaria). Agric. Ecosyst. Environ. 2013, 176, 39-52. [CrossRef]

55. Sun, J.; Qin, X.; Yang, J. The response of vegetation dynamics of the different alpine grassland types to temperature and precipitation on the Tibetan Plateau. Environ. Monit. Assess. 2016, 188, 20. [CrossRef] [PubMed]

56. Jiang, Y.; Tao, J.; Huang, Y.; Zhu, J.; Tian, L.; Zhang, Y. The spatial pattern of grassland aboveground biomass on Xizang Plateau and its climatic controls. J. Plant. Ecol. 2014, 8, 30-40. [CrossRef]

57. Li, W.; Liu, Y.; Wang, J.; Shi, S.; Cao, W. Six years of grazing exclusion is the optimum duration in the alpine meadow-steppe of the north-eastern Qinghai-Tibetan Plateau. Sci. Rep. 2018, 8, 17269. [CrossRef]

58. Chen, J.; Tang, H. Effect of grazing exclusion on vegetation characteristics and soil organic carbon of Leymus chinensis grassland in northern China. Sustainability 2016, 8, 56. [CrossRef]

59. Odriozola, I.; García-Baquero, G.; Fortin, M.J.; Laskurain, N.A.; Aldezabal, A. Grazing exclusion unleashes competitive plant responses in Iberian Atlantic mountain grasslands. Appl. Veg. Sci. 2017, 220, 50-61. [CrossRef]

(C) 2020 by the authors. Licensee MDPI, Basel, Switzerland. This article is an open access article distributed under the terms and conditions of the Creative Commons Attribution (CC BY) license (http://creativecommons.org/licenses/by/4.0/). 